Article

\title{
Toxicity, Pharmacokinetics, and Gut Microbiome of Oral Administration of Sesterterpene MHO7 Derived from a Marine Fungus
}

\author{
Wei Tian $₫$, Liang Yang, Di Wu, Zixin Deng and Kui Hong * \\ Key Laboratory of Combinatorial Biosynthesis and Drug Discovery, Ministry of Education, and Wuhan \\ University School of Pharmaceutical Sciences, Wuhan University, Wuhan 430071, China; twwtss@163.com (W.T.); \\ liangy@whu.edu.cn (L.Y.); diwu0301@163.com (D.W.); zxdeng@whu.edu.cn (Z.D.) \\ * Correspondence: kuihong31@whu.edu.cn; Tel.: +86-27-6875-2442
}

Received: 10 October 2019; Accepted: 25 November 2019; Published: 26 November 2019

check for updates

\begin{abstract}
Sesterterpene MHO7 derived from mangrove fungus is a novel estrogen receptor degrader for the treatment of breast cancer. To explore its safety and pharmacokinetics in vivo, Log P/D values, stability in simulated gastric/intestinal (SGF/SIF), toxicity, and pharmacokinetics studies were carried mainly by liquid chromatography technique coupled with tandem mass spectrometry (LC-MS/MS) method in mice, and the effect of MHO7 on mice gut microbiota at different time points was revealed by $16 \mathrm{~S}$ rRNA sequencing. Log P/D values ranged 0.93-2.48, and the compound in SGF and SIF is stable under the concentration of $5 \mathrm{mM} \cdot \mathrm{L}^{-1}$. The maximum tolerance dose (MTD) of oral administration in mice was $2400 \mathrm{mg} \cdot \mathrm{kg}^{-1}$. The main pharmacokinetics parameters were as following: $\mathrm{C}_{\max }$ of $1.38 \mu \mathrm{g} \cdot \mathrm{mL}^{-1}, \mathrm{~T}_{\max }$ of $8 \mathrm{~h}$, a half-life $\left(\mathrm{t}_{1 / 2}\right)$ of $6.97 \mathrm{~h}$, an apparent volume of mean residual time (MRT) of $8.76 \mathrm{~h}$, and an area under the curve (AUC) of $10.50 \mathrm{~h} \cdot \mu \mathrm{g} \cdot \mathrm{mL}^{-1}$. MHO7 displayed a wide tissue distribution in mice, with most of the compound in liver $\left(3.01 \pm 1.53 \mu \mathrm{g} \cdot \mathrm{g}^{-1}\right)$ at $1 \mathrm{~h}$, then in fat $\left(5.20 \pm 3.47 \mu \mathrm{g} \cdot \mathrm{g}^{-1}\right)$ at $4 \mathrm{~h}$, and followed by reproductive organs with the concentrations of $23.90 \pm 11.33 \mu \mathrm{g} \cdot \mathrm{g}^{-1}, 13.69 \pm 10.29 \mu \mathrm{g} \cdot \mathrm{g}^{-1}, 1.46 \pm 1.23 \mu \mathrm{g} \cdot \mathrm{g}^{-1}$, and $0.36 \pm 0.46 \mu \mathrm{g} \cdot \mathrm{g}^{-1}$ at $8,12,20$ and $30 \mathrm{~h}$, respectively. The most influenced genera of gut microbiome belonged to phylum Firmicutes (21 of 28), among which 18 genera originated from the order Clostridiales, class Clostridia, and families of Ruminococcaceae (11 of 18) and Lachnospiraceae (4 of 18). These results provide that MHO7 is suitable for oral administration in the treatment of breast cancer with the target organs of reproductive organs and regulation on Ruminococcaceae and Lachnospiraceae.
\end{abstract}

Keywords: MHO7; Log P/D values; Toxicity; Pharmacokinetics; Gut microbiome

\section{Introduction}

Of the more than 80,000 identified terpenoids [1], sesterterpenoids are amongst the rarest and are an attractive source of leading compounds with little more than 1000 compounds known [2]. In recent years, amounts of biological sesterterpenoids were isolated from the metabolites of marine microorganism [3], such as neomangicols and mangicols from marine-derived fungus Fusarium sp. and ophiobolins from marine-derived fungus Aspergillus spp. [4-6]. Ophiobolins (Ophs) are a very rare group of sesterterpenoids that bear a unique 5-8-5 tricarbocyclic in structure [5]. At present, 72 Ophs have been reported including 35 Ophs which were produced by marine-derived fungus [5,7-9]. The family shows significant inhibitory effects on the growth of a variety of cancer cells, drug-resistant cells, and cancer stem cells [5]. In total, 41 cell lines have been tested for 26 Ophs with the $\mathrm{IC}_{50}$ values ranging from $0.08 \mu \mathrm{M}$ to $85 \pm 12 \mu \mathrm{M}$ [5], which is considered to be potential drug candidates for cancer therapy. 
In our previous study, MHO7 (6-epi-ophiobolin G, the structure is shown in Figure 1), which was produced by a mangrove fungus Aspergillus ustus 094102 [10], demonstrated potent antitumor activity against breast cancer cells (MCF-7) by the mechanism of down regulating estrogen receptor alpha $(E R \alpha)$ acting as a novel estrogen receptor degrader different from the known ER $\alpha$ inhibitors [11].

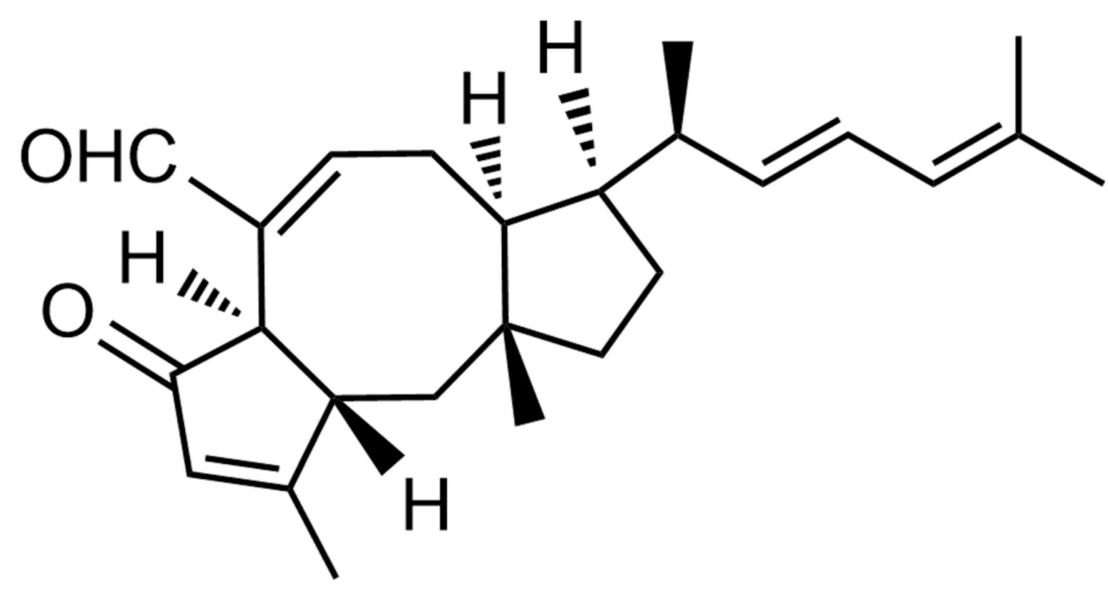

Figure 1. The structure of MHO7.

Although the family of Ophs have shown anticancer activity in some cancer cell lines [5], no toxicity and pharmacokinetics studies have been reported on these compounds. Due to the convenient administration, the oral route of drug administration is the most common approach comparing with injections (intravenous, intramuscular, and subcutaneous) or inhalation administration [12,13]. Drugs dissolve in the gastrointestinal tract after oral administration and then distribute throughout the body, which depends on the solubility in different $\mathrm{pH}$ environments of the compounds [13]. The liposolubility, safety, and pharmacokinetics study of compounds are very important in the early stage in drug development [14]. Recent studies discovered that gut microbiota influences host physiology including nutrient metabolism, resistance to infection, and immune system development $[15,16]$. It is also associated with diseases ranging from localized gastroenterologic disorders to neurologic, respiratory, metabolic, hepatic, and cardiovascular illnesses [15-18].

In this study, we first determined the oil/water partition coefficient in different $\mathrm{pH}$ environments and the stability in simulated gastric fluid (SGF) and simulated intestinal fluid (SIF) of MHO7. Then, we investigated acute toxicity of MHO7 in mice by oral administration. Based on these results, the pharmacokinetics and tissue distribution study of $\mathrm{MHO} 7$ in mice were carried out. Moreover, the effect of oral administration of MHO7 on gut microbiota at different time points was studied.

\section{Results and Discussion}

\section{1. $\log P$ and $\log D$ Value of $M H O 7$}

Log P value of MHO7 was carried out by measuring the solubility of MHO7 in n-octanol and water system at 25 and $37^{\circ} \mathrm{C}$, respectively. The Log D values of MHO7 at physiological conditions of stomach, intestine, and plasma were examined under three $\mathrm{pH}$ values of $1.5,5.0$, and 7.4, respectively. The result of HPLC methodological validation is shown in Table S1 and the Log P and Log D values were calculated, as listed in Tables S2 and S3. The $\log p$ values were $1.29 \pm 0.05$ and $2.48 \pm 0.03$ at $25^{\circ} \mathrm{C}$ and $37^{\circ} \mathrm{C}$, respectively. The Log D values were $1.12 \pm 0.03,0.93 \pm 0.02$, and $1.26 \pm 0.01$, respectively. Proudfoot et al. (2005) reviewed the oil-water distribution coefficients of 1791 oral medicines on the market in the past 60 years and there were $37 \%$ oral medicines with the $\log p$ values of $1-3$ and $22.6 \%$ of 3-5 [19], illustrating that the oil-water distribution coefficient parameter of MHO7 satisfies the oral preparation. 


\subsection{Stability of MHO7 in Simulated Gastric Fluid (SGF) and Simulated Intestinal Fluid (SIF)}

Simulated Gastric Fluid (SGF) and Simulated Intestinal Fluid (SIF) were prepared in the in vitro incubation system mainly containing pepsin and trypsin, respectively. Concentrations of MHO7 from each time point were obtained by liquid chromatography technique coupled with tandem mass spectrometry (LC-MS/MS) and the stability of MHO7 in SGF and SIF is shown in Figure 2, while the result of methodological validation is shown in Table S4 and Figure S1. Figure 2A exhibits that the deterioration of $\mathrm{MHO} 7$ reached the maximum at $2 \mathrm{~h}$ after addition and slowed after $2 \mathrm{~h}$ incubating in SGF and SIF with the concentrations of 0.05 and $0.5 \mathrm{mM} \cdot \mathrm{L}^{-1}$. At $8 \mathrm{~h}$, the percentage concentrations were $76.19 \pm 0.99 \%$ in SGF and $94.83 \pm 1.14 \%$ in SIF after adding MHO7 at $0.05 \mathrm{mM} \cdot \mathrm{L}^{-1}$; however, when the initial addition concentration was $0.5 \mathrm{mM} \cdot \mathrm{L}^{-1}$, the percentage concentrations of MHO7 were $80.2 \pm 3.15 \%$ in SGF and $89.74 \pm 0.86 \%$ in SIF, which revealed that MHO7 is more stable in SIF than in SGF. Figure 2B displays the effect of different concentrations of MHO7 on pepsin in SGF. The protein was precipitated immediately after adding MHO7 at $5 \mathrm{mM} \cdot \mathrm{L}^{-1}$, which was also observed in SIF of trypsin precipitation.

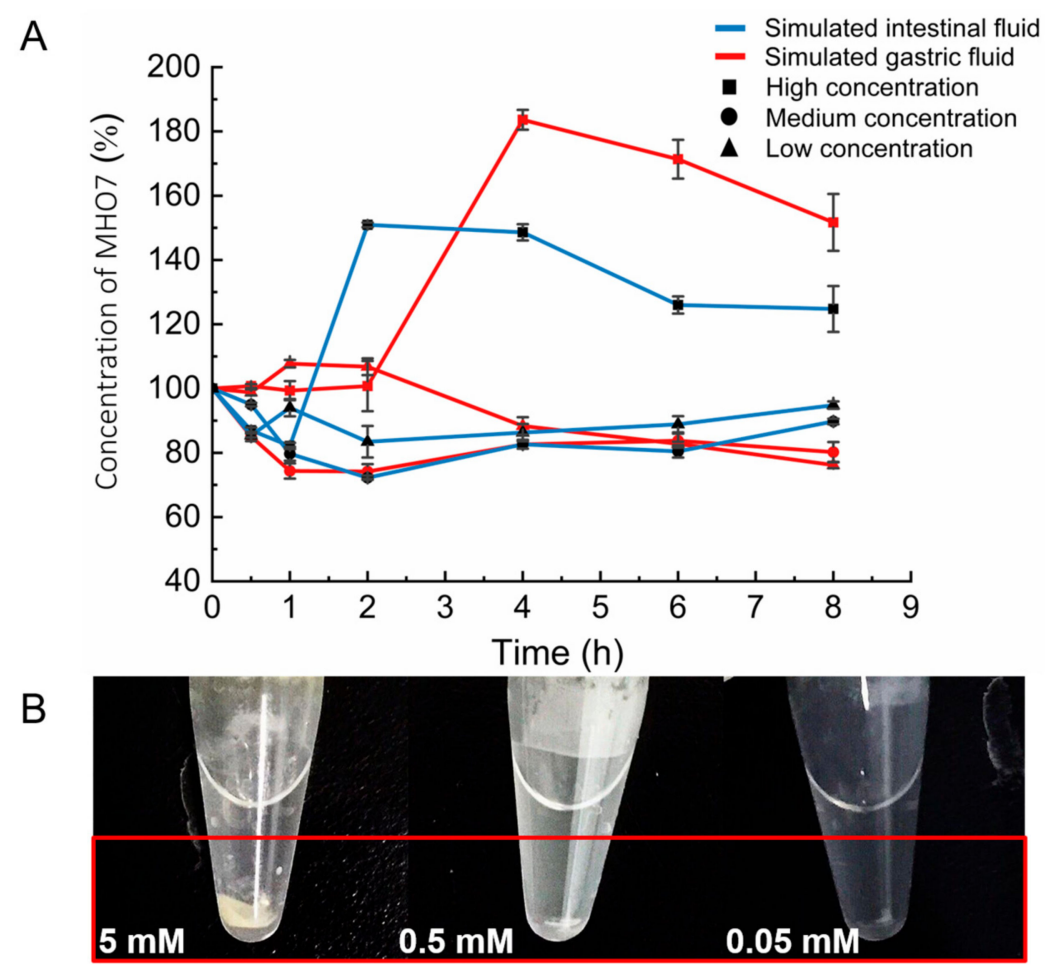

Figure 2. Stability of MHO7 in Simulated Gastric Fluid (SGF) and Simulated Intestinal Fluid (SIF): (A) effects on incubation system of different concentrations of MHO7; and (B) stability of different concentrations of MHO7 in SGF and SIF ( $n=3$ per group).

\subsection{Maximum Tolerable Dose of Oral Administration of MHO7 in Mice}

In total, 20 female and 20 male mice were used in the sighting study and main study on assessing the maximum tolerable dose (MTD) of MHO7. The MTD of MHO7 in both male and female KM mice was determined to be $2400 \mathrm{mg} \cdot \mathrm{kg}^{-1}$ by oral administration. Within 14 days after oral administration of MHO7, no animals died, and their weight increased with time (Figure S2). There was no significant difference between the MHO7 group and control group after seven days. The weight ranges are recorded in Table S5, which shows there was no significant difference between treatment group and control group. No obvious toxicity was observed, but a small number of animals with diarrhea was found during the first day in both female and male mice, and returned to normal within two days. The oral administration of MHO7 was well-tolerated by animals. 


\subsection{Pharmacokinetics and Tissue Distribution after Oral Administration of MHO7}

A HPLC-MS/MS method for the analysis of MHO7 in mice biological samples was developed. Calibration curves of MHO7 in plasma and different tissues were constructed by plotting the peak area ratio $(Y)$ of MHO7 to IS versus the nominal concentration $(X)$ of MHO7 with the standard curves $Y=$ $0.0486392+1.8329 \times X$, Correlation coefficient $R^{2}=0.9982$ for plasma and $Y=0.0608319+1.39753 \times$ $X, R^{2}=0.9976$ for tissues. The limits of quantification of MHO7 in mice plasma and tissues were 0.5 and $2.0 \mathrm{nM} \cdot \mathrm{L}^{-1}$, respectively. Then, the relative standard deviations (RSDs) were measured to be in the range of $4.23-6.94 \%$ for inter-day precision and $2.02-4.87 \%$ for intra-day precision. Moreover, the accuracy ranged $93.57-100.26 \%$ for inter-day and $92.50-101.15 \%$ for intra-day. In addition, the matrix effects and extraction recoveries of MHO7 in plasma and tissues were $90.05-100.63 \%$ and $90.09-93.97 \%$, respectively. Finally, the stability under a variety of storage and handling conditions of MHO7 was stable during the routine analysis for the pharmacokinetics and tissue distribution study. Other results of methodological validation are shown in Tables S6 and S7 and Figures S3 and S4.

The pharmacokinetics and tissue distribution following single oral administration of MHO7 at doses of $500 \mathrm{mg} \cdot \mathrm{kg}^{-1}$ are shown in Figure 3. After oral administration, MHO7 was absorbed rapidly at $4-8 \mathrm{~h}$ and reached its peak at about $8 \mathrm{~h}$ with the peak plasma concentration (Cmax) $1.38 \mu \mathrm{g} \cdot \mathrm{mL}^{-1}$, while the elimination of MHO7 was slow with a low concentration after $16 \mathrm{~h}$ (Figure $3 \mathrm{~A}$ ). The pharmacokinetics curve of MHO7 showed a little second peak at $20 \mathrm{~h}$, which illustrated that the secondary absorption of MHO7 possibly occurred in plasma. Pharmacokinetic parameters achieved after oral MHO7 are shown in Table 1. The area under the plasma concentration-time curve (AUC) was $10.50 \mathrm{~h} \cdot \mu \mathrm{g} \cdot \mathrm{mL}^{-1}$ and the volume of distribution $(\mathrm{V} / \mathrm{F})$ was $479.02 \mathrm{~L} \cdot \mathrm{kg}^{-1}$. The elimination half-life $\left(\mathrm{t}_{1 / 2}\right)$ was $6.97 \mathrm{~h}$, indicating that MHO7 was absorbed and cleared slowly from the mice plasma. The clearance $(\mathrm{CL} / \mathrm{F})$ and mean residence time (MRT) were $476.08 \mathrm{~L} \cdot \mathrm{h}^{-1} \cdot \mathrm{kg}^{-1}$ and $8.76 \mathrm{~h}$, respectively.

Table 1. Main pharmacokinetic parameters of MHO7 in mice plasma.

\begin{tabular}{cc}
\hline Parameter & Estimate \\
\hline Lambda_z & $0.10 \cdot \mathrm{h}^{-1}$ \\
$\mathrm{t}_{1 / 2}$ & $6.97 \mathrm{~h}$ \\
$\mathrm{~T}_{\max }$ & $8.00 \mathrm{~h}$ \\
$\mathrm{C}_{\max }$ & $1.38 \mu \mathrm{g} \cdot \mathrm{mL}^{-1}$ \\
$\mathrm{AUC}$ & $10.50 \mathrm{~h} \cdot \mathrm{\mu g} \cdot \mathrm{mL}^{-1}$ \\
$\mathrm{~V} / \mathrm{F}$ & $479.02 \mathrm{~L} \cdot \mathrm{kg}^{-1}$ \\
$\mathrm{CL} / \mathrm{F}$ & $47.61 \mathrm{~L} \cdot \mathrm{h}^{-1} \cdot \mathrm{kg}^{-1}$ \\
$\mathrm{MRT}$ & $8.76 \mathrm{~h}$ \\
\hline
\end{tabular}

The percentage of MHO7 in the stomach and intestine at different time points after oral administration of MHO7 is illustrated in Figure 3B. The percentage of MHO7 in the stomach was significantly greater than that in the intestine and reached maximum at $8 \mathrm{~h}$, which was consistent with the plasma concentration-time curve. Furthermore, the amount of MHO7 in the stomach and its contents was only $16.79 \%$ of the intake, and less than $5 \%$ in the intestine and its contents. As we known, oral drugs are absorbed through the gastrointestinal tract and enter the blood circulation. Although there was a little amount of $\mathrm{MHO} 7$ in the gastrointestinal tract and its contents, the $\mathrm{C}_{\max }$ of $\mathrm{MHO}$ in plasma was still low. The potential mechanism of low bioavailability might not be associated with the absorption in the gastrointestinal tract but plasma, such as a high plasma protein combination rate.

The MHO7 concentrations in other tissues were determined at 1, 4, 8, 12, 20 and $30 \mathrm{~h}$ after oral administration at a dose of $500 \mathrm{mg} \cdot \mathrm{kg}^{-1}$, as shown in Figure 3C. MHO7 was widely distributed into most tissues and declined progressively with time thereafter at the concentrations of 0.36-23.90 for the reproductive organs, $0.18-11.15$ for fat, $0.07-8.16$ for the kidney, $0.01-3.01$ for the liver, $0.08-2.34$ for the lung, $0.02-1.42$ for the muscle, $0.01-0.95$ for the brain, $0.04-0.85$ for the heart, and $0.01-0.48$ for the spleen, from high to low in the order of highest concentration, which indicates that there was 
no long-term accumulation of MHO7 and congruent with the observed change trend in the plasma concentration. Ratios of tissues to plasma concentration at each time point are exhibited in Figure 3D. MHO7 showed wide transportability into tissues with tissue/plasma concentration ratios of $>1000$ for the stomach and $>100$ for the intestines, $6.05-30.45$ for the reproductive organs, $0.18-17.40$ for the liver, 0.68-17.24 for the kidney, $2.33-14.03$ for fat, $0.28-8.55$ for the spleen, $0.72-6.84$ for the lung, $0.36-6.11$ for the brain, $0.99-5.54$ for the muscle, and $0.31-4.20$ for the heart, from high to low in the order of highest radios. The corresponding concentrations values of MHO7 in tissue biodistribution and ratios of tissues/plasma each time points are summarized in Tables S8 and S9.
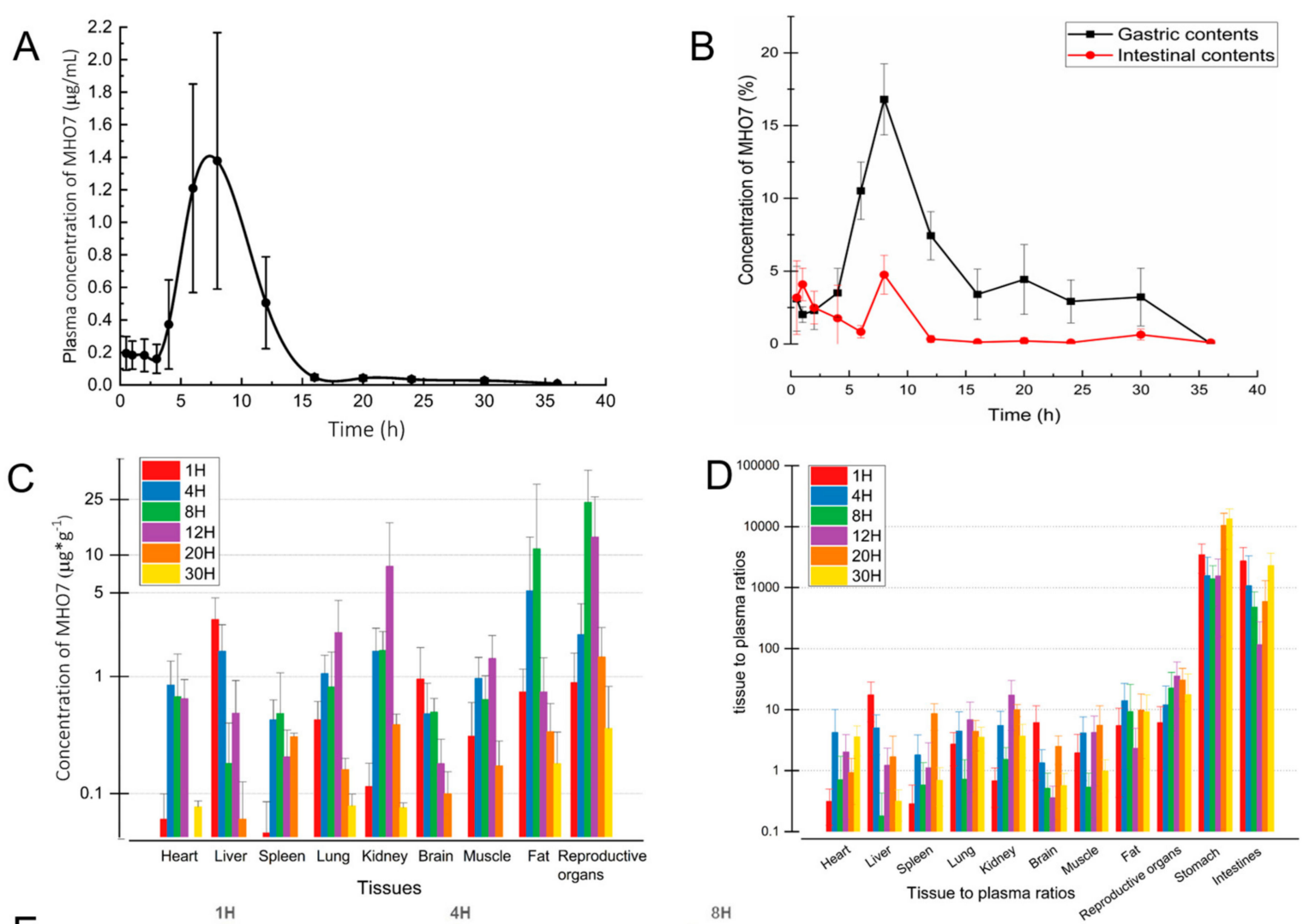

$E$

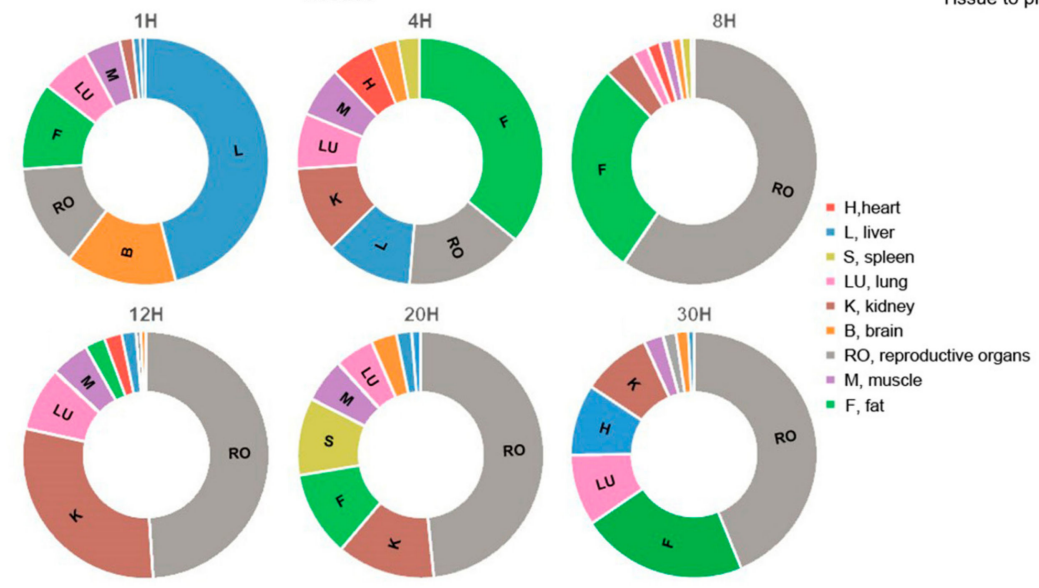

Figure 3. Pharmacokinetics and tissue distribution study of MHO7 in female mice at a signal oral administration dose of $500 \mathrm{mg} \cdot \mathrm{kg}^{-1}$ ( $n=6$ per group): (A) the plasma concentration-time curve of MHO7; (B) the percentage concentrations of MHO7 in the stomach and intestine at different time points; (C) the concentrations of MHO7 in tissues; (D) the ratios of tissues to plasma of MHO7; and (E) the pie chart of concentrations of MHO7 in tissues at different time points. 
The pie chart of concentrations of MHO7 in tissues is exhibited in Figure 3E. At $1 \mathrm{~h}$ after oral administration of $\mathrm{MHO} 7$, highest concentration levels were observed in liver $\left(3.01 \pm 1.53 \mu \mathrm{g} \cdot \mathrm{g}^{-1}\right)$, followed by brain $\left(0.95 \pm 0.80 \mu \mathrm{g} \cdot \mathrm{g}^{-1}\right)$ and reproductive organs $\left(0.88 \pm 0.68 \mu \mathrm{g} \cdot \mathrm{g}^{-1}\right)$. At $4 \mathrm{~h}$, the MHO7 was concentrated in fat $\left(5.20 \pm 3.47 \mu \mathrm{g} \cdot \mathrm{g}^{-1}\right)$, reproductive organs $\left(2.29 \pm 1.80 \mu \mathrm{g} \cdot \mathrm{g}^{-1}\right)$ and liver $\left(1.64 \pm 1.09 \mu \mathrm{g} \cdot \mathrm{g}^{-1}\right)$ in sequence. At $8 \mathrm{~h}$, the highest level of MHO7 was detected in reproductive organs $\left(23.90 \pm 11.33 \mu \mathrm{g} \cdot \mathrm{g}^{-1}\right)$, followed by fat $\left(11.15 \pm 8.87 \mu \mathrm{g} \cdot \mathrm{g}^{-1}\right)$ and kidney $\left(1.66 \pm 0.74 \mu \mathrm{g} \cdot \mathrm{g}^{-1}\right)$. However, at $12 \mathrm{~h}$, the levels of MHO7 from high to low were reproductive organs $\left(13.69 \pm 10.29 \mu \mathrm{g} \cdot \mathrm{g}^{-1}\right)$, kidney $\left(8.16 \pm 6.23 \mu \mathrm{g} \cdot \mathrm{g}^{-1}\right)$, and lung $\left(2.34 \pm 1.91 \mu \mathrm{g} \cdot \mathrm{g}^{-1}\right)$. Furthermore, the highest level was exhibited in reproductive organs with the concentration of $1.46 \pm 1.23 \mu \mathrm{g} \cdot \mathrm{g}^{-1}$ and $0.36 \pm 0.46 \mu \mathrm{g} \cdot \mathrm{g}^{-1}$ at $20 \mathrm{~h}$ and $30 \mathrm{~h}$, respectively.

The results indicate that $\mathrm{MHO} 7$ was widely distributed in most tissues and decreased obviously after $20 \mathrm{~h}$. In our previous study, MHO7 exhibited antitumor activity against breast cancer cells (MCF-7) by the mechanism of down regulating ER $\alpha$ [11]. Breast cancer occurs in female animals; in the pharmacokinetics experiments, especially tissue distribution, we studied whether MHO7 has potential for the treatment of breast cancer in female mice. In these organs, the concentration of MHO7 in reproductive organs was significantly higher than in other tissues during 8-30 h, which suggested that reproductive organs might be a main target organ for MHO7 with a sustained effect.

Furthermore, the concentration of MHO7 in liver at $1 \mathrm{~h}$ was obviously higher than in other tissues, illustrating that MHO7 metabolite in liver occurred firstly. In addition, the concentrations of MHO7 in kidney at $12 \mathrm{~h}$ were markedly higher than in other tissues except reproductive organs, which demonstrated the accumulation of MHO7 in kidney and suggested that renal excretion might be a main elimination route for MHO7. Finally, MHO7 exhibited a low concentration in the brain, spleen, and heart, which indicates that blood flow and the perfusion rate of the organ did not play a key role in the distribution of MHO7.

\subsection{Changes of Gut Microbiome in Mice after Oral MHO7}

To identify the effects in the compositional distribution of cecal microbiota induced by MHO7, the variable regions $\mathrm{V} 3-\mathrm{V} 4$ of $16 \mathrm{~S}$ rRNA gene of the cecal samples from different time groups after oral MHO7 was sequenced by Illumina HiSeq/MiSeq platforms. In total, 760 million 400-bp paired-end reads were generated, with an average length of $437 \mathrm{bp}$ of 1,262,525 sequences for each sample. To determine whether the sequencing adequately captured the diversity of the gut microbiota, rarefaction and Shannon index analysis was performed indicating that the sequencing depth was sufficient to cover most of the diversity (Figure S5). The results are presented as operational taxonomic units (OTUs) based on a sequence similarity of greater than $97 \%$ (Figure 4 ).

Principal coordinates analysis ( $\mathrm{PCOA})$ and Hierarchical clustering analysis revealed that a distinct clustering of the microbiota composition for each group (Figure 4A,B). After oral administration of MHO7, the microbial communities in the caeca of the MHO7-1 h group were more closely related to those of the control group, and the MHO7-8 $\mathrm{h}$ and MHO7-30 $\mathrm{h}$ groups had a distinct microbiota composition that clustered differently from the other two groups. At the OTU level, compared to the control group, the gut community diversity measured by the Shannon index decreased significantly in the MHO7-8 h group (Figure $4 \mathrm{C} ; p<0.05$ ). A remarkable reduction of gut community richness measured by the Sobs index (Figure 4D; $p<0.01$ ) and the amount of OTUs (Figure 4E; $p<0.001$ ) appeared in MHO7-8 h and MHO7-30 h groups, compared to the control group. However, there was no significant difference in richness, diversity, or OUT number of the gut microbiome between control and MHO7-1 h group, indicating that the effect of oral MHO7 to gut microbiome of mice was influenced over time. 

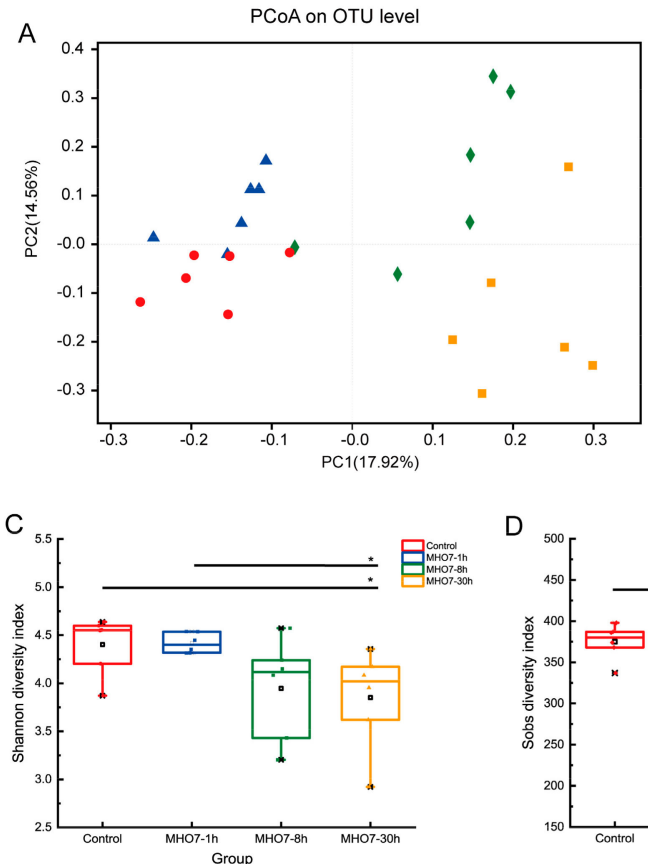

B

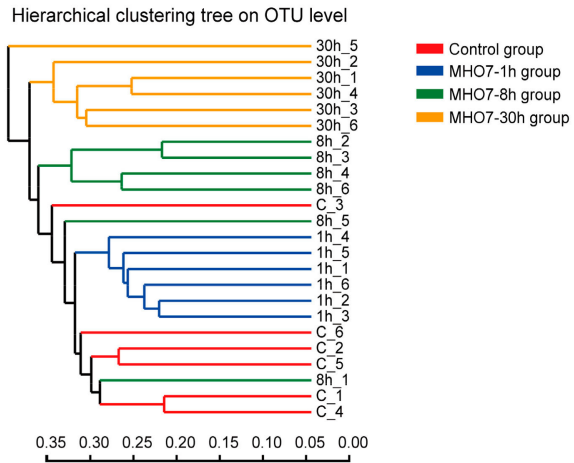

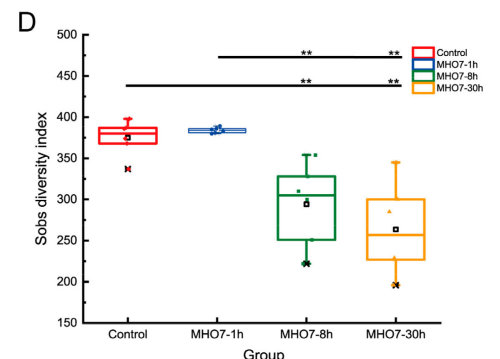

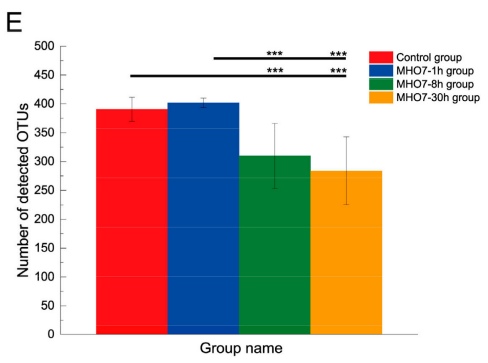

Figure 4. Modulation of structure and diversity of gut microbiota in different times after oral administration of $\mathrm{MHO}$ ( $n=6$ per group): (A) principal coordinate analysis (PCoA) and (B) sample clustering results of the unweighted UniFrac distances of microbial 16S rRNA sequences from the V3-V4 region; (C) alpha diversity analysis at the OTU level of Shannon index; (D) alpha diversity analysis at the OTU level of SOBS index; and (E) number of detected OTUs. Significant differences between control and drug groups are indicated: ${ }^{*} p<0.05 ;{ }^{* *} p<0.01 ;{ }^{* * *} p<0.001$.

To analyze the differences among control and treatment groups, a supervised comparison of the microbiota between control and treatment groups was performed by linear discriminant analysis (LDA) and effect size analysis (LEfSe) without any adjustments, which are often used to identify the specific bacterial taxa among different groups. The greatest differences in taxa between each treatment time and the identified key phylotypes as microbiological markers at various phylogenetic levels are shown in Figure 5. The taxonomic levels of the circles from inside to outside are phylum, class, order, family, and genus. We used a logarithmic LDA score threshold $>2$ to identify significant taxonomic differences between the control and drug groups (Figure S6). Since many bacteria in mice gut have not yet been identified at the species and even OTU levels, we analyzed gut microbiota from phylum to genus level.

Taxonomic representations of the significantly different taxa (cladogram) between control and treatment groups are shown in Figure 5, highlighting the relationship between taxa at different taxonomic levels in a tree-like structure and revealing how the significantly different taxa are interrelated. LEfSe revealed that the phylum and its derivative. After oral administration of MHO7 in treatment groups, the major changes were: Tenericutes, Saccharibacteria phylum, Bacteroidales_S24-7_group family and their immediate subordinate taxa at $1 \mathrm{~h}$; Proteobacteria phylum, Bacilli class and its subordinate taxa at $8 \mathrm{~h}$; and Deferribacteres, Verrucomicrobia phylum, Erysipelotrichia, and their subordinate taxa at $30 \mathrm{~h}$. However, no significant differences were demonstrated for predominant taxa Firmicutes and Bacteroidetes after oral administration of MHO7. 

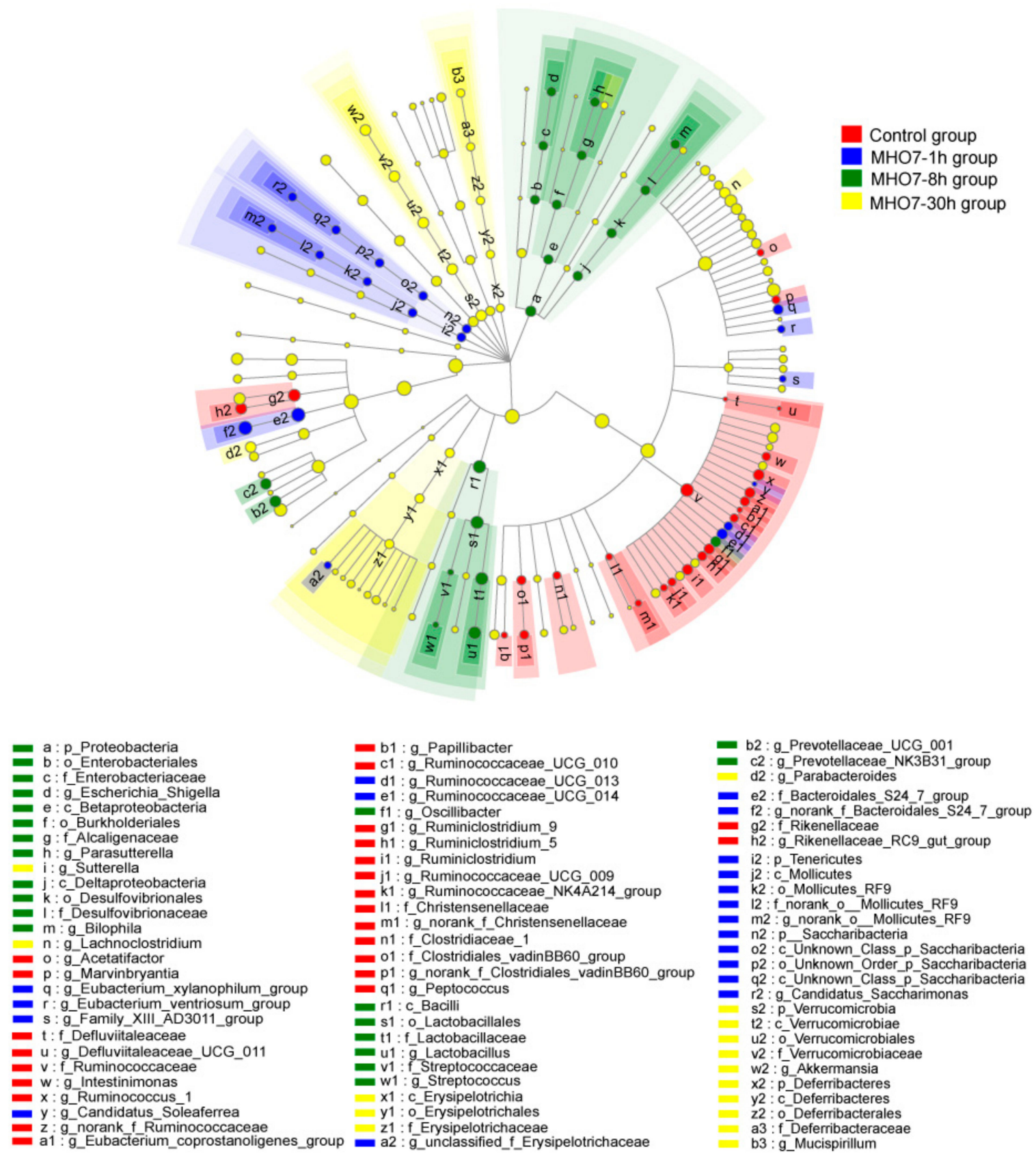

Figure 5. LEfSe results on gut microbiota in drug groups compared with control group. Difference are represented in the color of the most abundant class. Each circle's diameter is proportional to the taxon's abundance.

To profile specific changes after oral MHO7 at different times in gut microbiota community of mice from a taxonomic perspective, the taxon tree from phylum to genus is constructed in Figure 6 based on the significant difference genera of the gut microbiota in mice by analyzing the relative abundance differences of four groups at different taxonomic levels in Tables S10-S14 and Figure S7. 


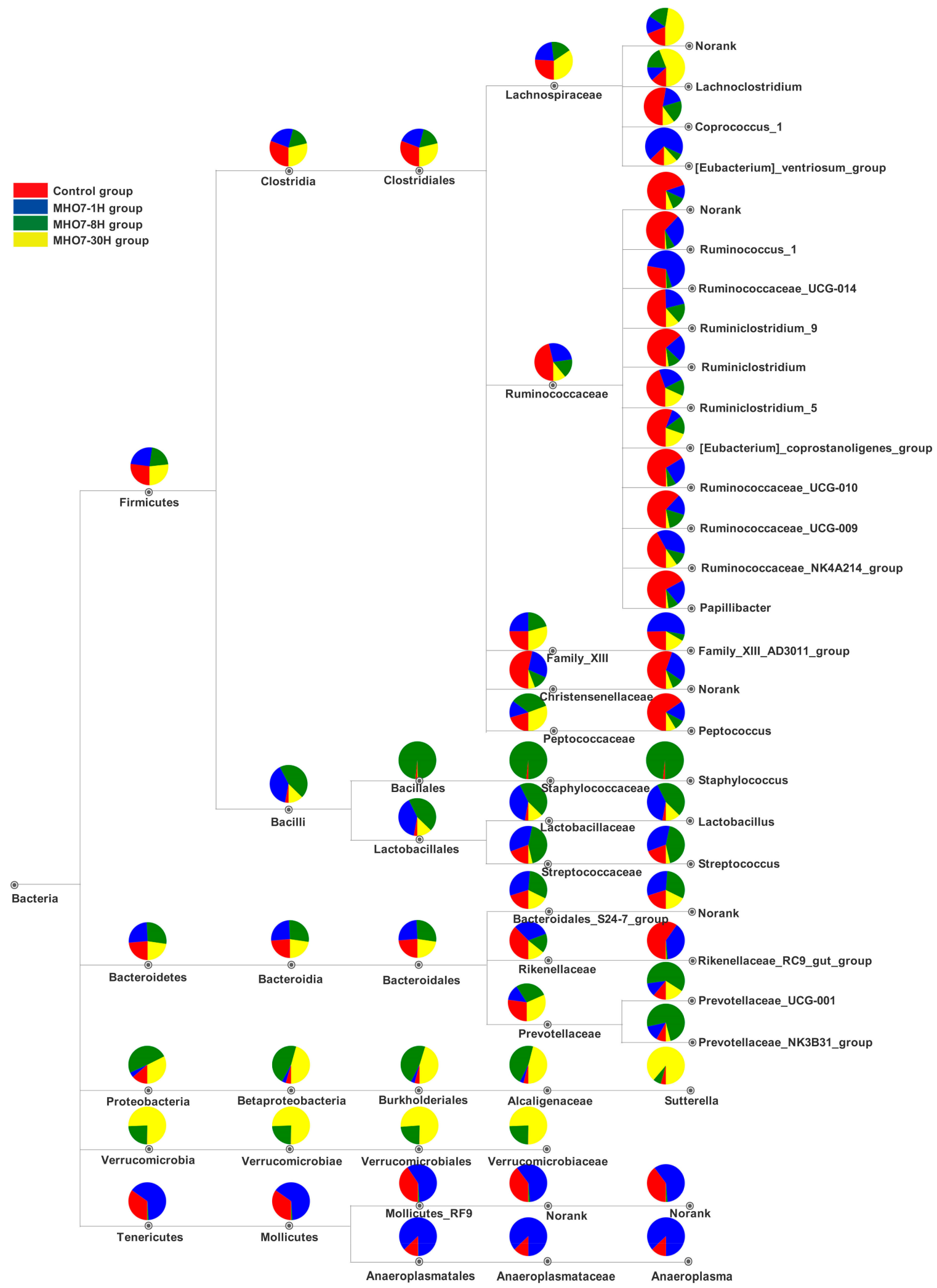

Figure 6. The taxon tree created based on the significantly different genera of the gut microbiota in female mice after oral administration of MHO7 at different time points of a signal dose of $500 \mathrm{mg} \cdot \mathrm{kg}^{-1}$.

At the phylum level, Firmicutes and Bacteroidetes were the dominant bacterial communities in all samples (Figure S7A) and there were no significant differences after oral administration of MHO7 at 
1, 8 or 30 h (Figure 6). However, other low abundance phyla, Proteobacteria, and Verrucomicrobia presented increased abundance in MHO7-8 $\mathrm{h}$ and $-30 \mathrm{~h}$ groups in contrast to Tenericutes (Figure 6). Previous studies revealed that the increased abundance of Proteobacteria was associated with intestinal dysbiosis, metabolic disorders, inflammatory bowel disease, and lung diseases [20,21]. Verrucomicrobia was considered to be potential to induce regulatory immunity [22].

At the class level, MHO7 markedly diminished the level of Clostridia at $1 \mathrm{~h}(38.58 \pm 11.1 \%)$ and $8 \mathrm{~h}(28.98 \pm 20.11 \%)$ after oral administration when compared to control group $(51.23 \pm 18.09 \%)$, but the reduction was recovered at $30 \mathrm{~h}(47.82 \pm 20.66 \%)$ (Figure 5 and Table S10); in contrast, the relative abundance of Bacilli remarkedly enriched at $1 \mathrm{~h}$ and $8 \mathrm{~h}$, and reversed at $30 \mathrm{~h}$ (Figure 5), which revealed that the influence of $\mathrm{MHO}$ on these classes was recoverable over time. The relative abundance of Mollicutes was significantly raised at $1 \mathrm{~h}$ and reduced at 8 and $30 \mathrm{~h}$. Furthermore, when compared with control and MHO7-1 h groups, respectively, the increase of Verrucomicrobiae, Betaproteobacteria was noteworthy differences in MHO7-8 $\mathrm{h}$ and $-30 \mathrm{~h}$ groups. At the order level, Clostridiales, Bacillales, Lactobacillales, Burkholderiales, Verrucomicrobiales, Mollicutes_RF9, and Anaeroplasmatales exhibited consistent trends at the class level.

At the family level, the relative abundance of Ruminococcaceae, Christensenellaceae, and Rikenellaceae displayed a sustained reduction at 1,8 and $30 \mathrm{~h}$ after oral administration of MHO7 comparing with control group. The level of Lachnospiraceae and Family_XIII was declined in MHO7-1 $\mathrm{h}$ and $-8 \mathrm{~h}$ groups but raised again in MHO7-30 $\mathrm{h}$ group when compared with control group. To the contrary, the relative abundance of Lactobacillaceae, Streptococcaceae, and Bacteroidales_S24-7_group was increased in MHO7-1 $\mathrm{h}$ and $-8 \mathrm{~h}$ groups and decreased in MHO7-30 $\mathrm{h}$ group. The level of Peptococcaceae, Prevotellaceae, Alcaligenaceae, and Verrucomicrobiaceae was reduced at $1 \mathrm{~h}$ and increased at 8 and $30 \mathrm{~h}$ after oral administration of MHO7. On the contrary, norank_o__Mollicutes_RF9 and Anaeroplasmataceae were increased in MHO7-1 h group and decreased in MHO7-8 $\mathrm{h}$ and $-30 \mathrm{~h}$ groups.

The relative abundance of Ruminococcaceae was enriched in breast cancer case patients, while the Lachnospiraceae were relatively less abundant $[23,24]$. The influence of MHO7 on downregulation of Ruminococcaceae and upregulation of Lachnospiraceae indicated that it has potential in the treatment of breast cancer. However, the families Lachnospiraceae, Ruminococcaceae, Christensenellaceae, Bacteroidaceae, Lactobacillaceae, and Rikenellaceae were reported to be associated with visceral fat, which resulted in cardio-metabolic disease risk and obesity [25-27]. Moreover, Mokkala et al. (2017) investigated that the relative abundance of the Ruminococcaceae might lead to a higher odds of positive gestational diabetes (GDM) in diagnosis [28], which revealed that MHO7 reducing the level of family Ruminococcaceae was beneficial to GDM. However, it is worth noting that the decrease of Ruminococcaceae and increase of Streptococcaceae might be a risk for cirrhosis [29] and IBD [30].

At the genus level, Figure 5 displays that 28 genera showed significant variation after oral administration of MHO7 with the dominated genera being $g \_$norank_f_Bacteroidales_S24-7_group, $g \_n o r a n k \_f \_$_achnospiraceae, Lactobacillus, and Rikenellaceae_RC9_gut_group in all groups (Figure S7J). The levels of Coprococcus_1, g_norank_f_Ruminococcaceae, Ruminococcus_1, Ruminiclostridium_9, Ruminococcaceae_UCG-010, Ruminococcaceae_UCG-009, g_norank_f_Christensenellaceae, Papillibacter, Peptococcus, Ruminiclostridium, and Rikenellaceae_RC9_gut_group were characterized by a continuous decline at 1,8 , and $30 \mathrm{~h}$ after oral administration of MHO7. The genera g_norank $f$ _Lachnospiraceae, Lachnoclostridium, Sutterella, and [Eubacterium]_coprostanoligenes_group decreased in MHO7-1 $\mathrm{h}$ group and enriched in MHO7-8 $\mathrm{h}$ and $-30 \mathrm{~h}$ groups as compared with control group. In contrast, the genera [Eubacterium]_ventriosum_group, Ruminococcaceae_UCG-014, Ruminococcaceae_NK4A214_group, norank_o_Mollicutes_RF,9 and Anaeroplasma increased at $1 \mathrm{~h}$ and reduced at 8 and $30 \mathrm{~h}$ after oral administration. The investigations indicated that, in high-fat diet-fed mice gut, the genera abundances of Ruminiclostridium and Ruminococcaceae UCG-009 were elevated while Ruminococcus_1, Ruminococcaceae_NK4A214_group, Ruminococcaceae_UCG-009, Ruminococcaceae_UCG-010, and Ruminiclostridium_9 were decreased [31-33]. However, in the 
isoproterenol-induced acute myocardial ischemia model, the amounts of Rikenellaceae RC9 gut group, Ruminococcus 1, and Bacteroidales S24-7 group were elevated while Ruminiclostridium 9, Lachnoclostridium, and Ruminococcaceae UCG-014 were reduced. The enrichments of Ruminiclostridium 5 and Rikenellaceae RC9 gut group were considered to be related to the lipid metabolism [34,35]. Furthermore, genus Ruminiclostridium 9 was positive to blood IgM level and colitis histological scores [36] and Anaeroplasma was supposed to be a potential anti-inflammatory probiotic for the treatment of chronic intestinal inflammation [37]. The researchers illustrated that, although the impact of MHO7 on these genera was not entirely consistent as reported but it mediated intake metabolism and inflammatory responses.

In addition, the amounts of $g \_n o r a n k \_f \_B a c t e r o i d a l e s \_S 24-7 \_g r o u p$, Prevotellaceae_UCG-001, Lactobacillus, Streptococcus, and Prevotellaceae_NK3B31_group was enriched in MHO7-1 h and $-8 \mathrm{~h}$ groups and reduced in MHO7-30 h group compared with control group. The reduction of genus Lactobacillus was associated with cardiovascular diseases (CD), inflammatory bowel disease (IBD), and chronic kidney disease [29,38], illustrating that MHO7 was beneficial to these diseases. Generally, most of the intestinal microbes influenced by MHO7 were the producers of short-chain fatty acids (SCFA), mainly acetate, propionate, and butyrate, which are believed to play a beneficial role in human gut health [39]. The correlation analysis illustrated that the genera Ruminococcaceae_UCG-010 and Ruminococcaceae_UCG-014 had a negative correlation with SCFA $[31,40]$ while the Ruminococcaceae NK4A214 group and Ruminococcaceae UCG-005 had a positive correlation with the SCFA [33,41]. Bacteroidales_S24-7_group family produces acetate, propionate, and succinate [42] and Coprococcus_1 genus can reduce the production of propionic acid [43]. In conclusion, viewed from intestinal microflora, MHO7 influenced the metabolic pathways by SCFA through regulating the level of gut microbiome.

\section{Materials and Methods}

\subsection{Chemicals and Reagents}

MHO7 (purity $\geq 98 \%$ ) was obtained from the fermentation products of Aspergillus ustus isolated from mangrove rhizosphere. The compound was isolated by column chromatography and the purity was controlled by HPLC using the standard curves for quantitative detection. Progesterone (IS), acetonitrile and methanol (HPLC grade), n-octanol, pepsin, trypsin, sodium dihydrogen phosphate, disodium hydrogen phosphate, dilute hydrochloric acid, sodium hydroxide, potassium dihydrogenphosphate, and dipotassium hydrogenphosphate were purchased from Sigma-Aldrich (St. Louis, MO, USA). Ultrapure water was obtained from distilled water using a Milli-Q system (Millipore, Milford, MA, USA).

\subsection{Instrumental Analysis Method of HPLC and LC-MS}

\subsubsection{HPLC Conditions}

An HPLC system (Shimadzu, Japan) was equipped with a LC-20AD binary pump system, a SIL-20AD auto sampler, a CBM-20A system controller, and a CTO-20A oven. Separation of MHO7 and IS from endogenous substances was carried out on an Agilent Zorbax XDB C18 column (5 $\mu \mathrm{m}, 250 \times$ $4.6 \mathrm{~mm}$, Agilent, Pal Alto, CA, USA), which was kept at $30^{\circ} \mathrm{C}$. The mobile phase was composed of $30 \%$ phase $\mathrm{A}$ (water) and $70 \%$ phase $\mathrm{B}$ (acetonitrile) with a flow rate of $1 \mathrm{~mL} \cdot \mathrm{min}^{-1}$. The inject volume of the sample solution was $10 \mu \mathrm{L}$.

\subsubsection{LC-MS/MS Conditions}

Chromatographic separation was achieved using the HPLC system (Thermo Scientific Accela ${ }^{\mathrm{TM}}$, Thermo Fisher Scientific, San Jose, CA, USA), equipped with a quaternary pump system, a de-gasser, a diode-array detector, an autosampler, and a column oven. Separation of MHO7 and IS from endogenous substances was carried out on a Waters CORTECS C18 column $(2.7 \mu \mathrm{m}, 150 \times 4.6 \mathrm{~mm}$, Waters, Milford, MA, USA), which was kept at $30^{\circ} \mathrm{C}$. The mobile phase is composed of phase A (water) 
and phase $\mathrm{B}$ (acetonitrile) with a flow rate of $0.4 \mathrm{~mL} \cdot \mathrm{min}^{-1}$. The gradient elution used to achieve chromatographic separation was as follows: $0-5 \mathrm{~min}, 10 \% \mathrm{~B} ; 5-8 \mathrm{~min}, 10-70 \% \mathrm{~B} ; 8-12 \mathrm{~min}, 70 \% \mathrm{~B}$; 12-18 $\mathrm{min}, 70-95 \% \mathrm{~B} ; 18-27 \mathrm{~min}, 95 \% \mathrm{~B}$; and $27-30 \mathrm{~min}, 95-10 \% \mathrm{~B}$. The inject volume of the sample solution was $10 \mu \mathrm{L}$ and the autosampler temperature was maintained at $10^{\circ} \mathrm{C}$.

Mass spectrometric analysis was carried out on a Thermo Scientific TSQ Quantum MS/MS system equipped with an electrospray ionization interface (ESI). Compound dependent parameters and instrumental parameters were optimized by infusing neat solutions of MHO7 and the IS separately by using a syringe pump. A selective-reaction monitoring (SRM) mode was applied for the detection of the transition of $\mathrm{m} / \mathrm{z} 367.3 \rightarrow 349.2,307.2 \mathrm{~m} / \mathrm{z}$ for MHO7 and $\mathrm{m} / \mathrm{z} 315.4 \rightarrow 109.2,97.0 \mathrm{~m} / \mathrm{z}$ for progesterone (IS), respectively. The typical operating source conditions for MS scan in positive ion ESI mode were optimized as follows: sheath gas flow rate, 20; Aux gas flow rate, 5; spray voltage, $3.50 \mathrm{kV}$; capillary temperature, $320{ }^{\circ} \mathrm{C}$; tube lens, $75.2 \mathrm{~V}$ of MHO7 and $89.1 \mathrm{~V}$ of IS; and collision energy, $13 \mathrm{~V}$ and $11 \mathrm{~V}$ of MHO7 (product ion 349.2, $307.2 \mathrm{~m} / \mathrm{z}$ ) and $28 \mathrm{~V}$ and $20 \mathrm{~V}$ of IS (product ion 109.2, $97.0 \mathrm{~m} / \mathrm{z}$ ), respectively.

\subsection{Bioanalytical Method Validation}

The LC-MS/MS method was validated according to the U.S. Food and Drug Administration (FDA) guidance for bioanalytical method validation [44].

\subsubsection{Specificity and Selectivity}

The specificity and selectivity of the method were investigated by the screening analysis of incubation system solutions and six individual blank mice plasma and tissues samples. Two other incubation system solutions and blank plasma and tissues samples containing an IS concentration of $5.0 \mathrm{mM} \cdot \mathrm{L}^{-1}$ were also determined for interference. Each blank sample was tested for exclusion of endogenous interference at the retention times of MHO7 and IS.

\subsubsection{Linearity and Lower Limit of Quantification (LLOQ)}

The linearity of the method was evaluated by using six calibration standards over a calibration range of $0.01-2 \mathrm{mM} \cdot \mathrm{L}^{-1}$ in oil-water system, $0.01-5 \mu \mathrm{M} \mathrm{L}^{-1}$ in the in vitro incubation system (SGF), $0.01-5 \mu \mathrm{M} \cdot \mathrm{L}^{-1}$ in plasma, $0.005-5$ and $0.05-50 \mu \mathrm{M} \cdot \mathrm{L}^{-1}$ in gastrointestinal contents, and $0.005-5$ and $0.5-50 \mu \mathrm{M} \cdot \mathrm{L}^{-1}$ in mice liver. LLOQ was determined as the lowest concentration of analytes with \%CV (coefficient of variation) not exceeding $20 \%$ and accuracy in the range of $80-120 \%$.

\subsubsection{Precision and Accuracy}

Intra- and inter-batch precision and accuracy of the developed method were investigated by analyzing QC samples at four different concentrations for six replicates. The precision of the method was determined by $\% \mathrm{CV}$ and accuracy was evaluated by recovery. As per US-FDA guidelines the acceptable limit of $\%$ CV was $<20 \%$ for LLOQ and $\leq 15 \%$ for HQC, MQC, and LQC. The accuracy was calculated as percent difference in mean value of the observed concentration and nominal concentrations of QC samples.

\subsubsection{Extraction Recovery and Matrix Effect}

The extraction recovery and matrix effects were investigated at $\mathrm{HQC}, \mathrm{MQC}$, and LQC concentration levels. Extraction recovery of MHO7 in SGF, mice plasma, and tissues was evaluated by comparing peak area ratios of MHO7 to IS of an extracted sample $(n=6)$ to the standard analytes solution of same concentration. To study matrix effect, initially, blank SGF, plasma, and tissue samples were processed followed by spiking of the analyte MHO7 and IS to the post processed samples. Further, aqueous solutions of analyte and IS of the same concentrations were prepared and analyzed. The matrix effect was calculated using the equation in the range of $0.8-1.2$. 


\subsubsection{Stability Studies}

To evaluate the stability of MHO7 in SGF, plasma, and tissues samples, six replicates of high- and low-quality control samples were analyzed. Post preparative stability was carried out at $10^{\circ} \mathrm{C}$ for $48 \mathrm{~h}$. The bench top and long-term stability were analyzed at ambient temperatures $25^{\circ} \mathrm{C}$ for $48 \mathrm{~h}$, and $-80^{\circ} \mathrm{C}$ for 30 days, respectively. For freeze-thaw stability, quality control samples were stored at $-80^{\circ} \mathrm{C}$. After three freeze-thaw cycles, quality control samples were analyzed. The stability was assessed by comparing with nominal concentration of the analyte at $0 \mathrm{~h}$ and the mean percentage changes are within the acceptance criteria of $\pm 10 \%$.

\subsection{Determination of Log P and Log D Value of MHO7 by Shaking Flask Method}

$\log \mathrm{P}$ value of $\mathrm{MHO} 7$ between n-octanol and water was determined at 25 and $37^{\circ} \mathrm{C}$, respectively. Log D value of MHO7 between n-octanol and phosphate buffer under three different $\mathrm{pH}$ ( $\mathrm{pH}$ 1.5, 5.0, and 7.4) systems were determined at $37^{\circ} \mathrm{C}$. The phases of distilled water and n-octanol were saturated with each other by shaking for $48 \mathrm{~h}$ with $250 \mathrm{rpm}$ in a shaking water bath prior to use. Solutions of MHO7 was prepared in concentration of $10 \mathrm{mM} \cdot \mathrm{L}^{-1}$ in n-octanol. Accurately measured amounts of the two solvents with necessary quantity of $\mathrm{MHO} 7$ were placed in a $5.0 \mathrm{~mL}$ centrifuge tube; then, the mixture was carried out at $250 \mathrm{rpm}$ and designated temperature in the shaking water bath for $48 \mathrm{~h}$ to afford complete phase separation. The samples of both phases were collected at $0,4,8,12,24,30,36$ and $48 \mathrm{~h}$, diluted with methanol $(1: 1, V)$ and determined by HPLC with the detection wavelength of $234 \mathrm{~nm}$. Each set of solvent systems for experimental $\log \mathrm{P} / \mathrm{D}$ value was the mean of the three determinations.

\subsection{SGF and SIF Stability of MHO7}

SGF was prepared with modifications according to Lee et al. (2012) by mixing $100 \mathrm{~mL}$ of distilled water with a $\mathrm{pH}$ value set to 2.0 with hydrochloric acid and $1 \mathrm{~g}$ pepsin solution $(800-2000 \mathrm{U} / \mathrm{mg}$ of protein). SIF was produced according to USP specifications (Test Solutions, United States Pharmacopeia 35 , NF 30, 2012). Monobasic potassium phosphate ( $0.68 \mathrm{~g})$ was dissolved in $25 \mathrm{~mL}$ of water. Then, $7.7 \mathrm{~mL}$ of $0.2 \mathrm{M} \mathrm{NaOH}$ was added to adjust the $\mathrm{pH}$ to 6.8 . To this, $1 \mathrm{~g}$ of pancreatin was added and shaken gently until dissolved and the volume adjusted to $100 \mathrm{~mL}$ with water. Pancreatin was added after adjusting the $\mathrm{pH}$ of the solution to 6.8 to avoid precipitation of the enzyme.

Aliquots $(199 \mu \mathrm{L})$ of SGF and SIF were placed in $1.5 \mathrm{~mL}$ microcentrifuge tubes and incubated at $37^{\circ} \mathrm{C}$ for $10 \mathrm{~min}$ in a water bath, respectively. Different concentrations of MHO7 $(1 \mu \mathrm{L})$ were added to each of the above microcentrifuge tubes to start the reaction with being incubated at $37^{\circ} \mathrm{C}$ at $250 \mathrm{rpm}$ in a shaking water bath. The reaction was stopped by adding ice ACN $(800 \mu \mathrm{L})$ to each tube at intervals of $0,0.5,1,2,4,6$, and $8 \mathrm{~h}$. The samples were vortexed for $15 \mathrm{~min}$ and centrifuged at $4{ }^{\circ} \mathrm{C}$ and $15,000 \mathrm{rpm}$ for $15 \mathrm{~min}$. After centrifuging the supernatant layer was taken directly for LC-MS analysis. Each experiment was carried out in triplicate, and average values were plotted. QC samples were prepared in the same way of inactivating pepsin in SGF incubation system at the concentrations of $1,0.1$ and $0.01 \mu \mathrm{M} \cdot \mathrm{L}^{-1}$ for HQC, MQC and LQC, respectively.

\subsection{Animals and Treatment}

Male and female KM mice of 8-10 weeks of age (20-22 g) were used in acute toxicity experiment and only female KM mice were subjected in other animal experiments. All mice were purchased from the Vital River Laboratory Animal Technology Co. Ltd. (Beijing, China). The mice were bred in a standard environment $\left(23 \pm 1{ }^{\circ} \mathrm{C}\right.$; humidity of $\left.60 \pm 5 \%\right)$ with a 12-h light/dark cycle and food and water were provided ad libitum. All animal protocols were approved by the Animal Care and Use Committee of Wuhan University Center for Animal Experiment ABSL-III Laboratory and complied with the Guide for the Care and Use of Laboratory Animals (NIH publication, 8th edition, 2011). In total, 130 mice were used for in vivo studies under the ethical approved protocols. 


\subsection{Determination of the Maximum Tolerated Dose (MTD) of MHO7 in Mice}

Male and female KM mice of 8-10 weeks of age (20-22 g) were used in acute toxicity experiment. After animals were acclimatized for 1 week, 20 female and 20 male mice were randomly and evenly divided into four groups. The mice of acute toxicity experiment were fasted overnight and administered by the oral dose of MHO7 $\left(2400 \mathrm{mg} \cdot \mathrm{kg}^{-1}\right.$, bw) diluted in corn oil the next morning. Then, mice were placed with free access to chow and water. The mice were observed for two weeks in all groups, and the weight was recorded at $0,1,7$, and 14 days. The number surviving and their behaviors was also recorded every day.

\subsection{Pharmacokinetic Studies Assay}

Ninety female KM mice of 8-10 weeks of age (20-22 g) were divided randomly into 15 groups, and, after fasting for $12 \mathrm{~h}$, the mice in other experiments were oral administrated at the dose of $500 \mathrm{mg} \cdot \mathrm{kg}^{-1} \mathrm{bw}$. About $500 \mu \mathrm{L}$ blood samples were collected at $0.5,1,2,3,4,5,6,8,10,12,16,20,24$, 30 and $36 \mathrm{~h}$ into heparinized tubes after the intragastric administration of MHO7. All blood samples were immediately centrifuged at $8000 \mathrm{~g}$ for $5 \mathrm{~min}$ and the resulting plasma was transferred and then processed as described in sample preparation for the analysis by LC-MS/MS. MHO7 levels in plasma were quantified by HPLC-MS/MS. The calibration curve was constructed by plotting the peak area ratio of $\mathrm{MHO} 7$ to the internal standard and the linearity was determined by weighted $(1 / \mathrm{x})$ linear regression analysis. The regression equation of the calibration curve was then used to calculate the concentration of MHO7 in the plasma. QC samples and standard curve series solutions were prepared in the same way of blank plasma. The concentrations of HQC, MQC, and LQC were 5, 0.5, and $0.05 \mu \mathrm{M} \cdot \mathrm{L}^{-1}$, respectively, and the concentrations of standard curve series solutions were $5,2.5,1,0.5$, $0.25,0.1,0.05$, and $0.01 \mu \mathrm{M} \cdot \mathrm{L}^{-1}$.

\subsection{Tissue Distribution Study Assay}

The animals and treatment methods were the same as in the pharmacokinetic studies. Afterwards, the biological samples ( $n=6$ per group) were collected at $1,4,8,12,20$, and $30 \mathrm{~h}$, and the tissues including heart, liver, spleen, lung, kidney, stomach, intestine, brain, muscle (hind limb), fat (white adipose tissue ), reproductive organs (uterus, fallopian tube and ovary) stomach and its contents, and intestine and its contents, and the blood samples were simultaneously collected. All the tissues were washed with cold physiological saline $\left(4^{\circ} \mathrm{C}\right)$, excess fluid blotted, accurately weighed, and subjected to the processing as described in the sample preparation. QC samples and standard curve series solutions were prepared in the same way of blank gastrointestinal contents and livers, respectively. The concentrations of $\mathrm{HQC}, \mathrm{MQC}$, and LQC in mice tissues were 10,1 , and $0.1 \mu \mathrm{M} \cdot \mathrm{L}^{-1}$, respectively, and the concentrations of standard curve series solutions were 50, 25, 10, 5, 2.5, 1, 0.5, 0.25, 0.1, and $0.005 \mu \mathrm{M} \cdot \mathrm{L}^{-1}$ for high and low concentrations of standard curves.

\subsection{Gut Microbiota Analysis}

\subsubsection{Sample Collection}

Fresh cecal samples from 24 ( $n=6$ per group) mice were collected at 1,8 and $30 \mathrm{~h}$ after oral administration of $500 \mathrm{mg} \cdot \mathrm{kg}^{-1} \mathrm{MHO}$ meanwhile control group was collected at $8 \mathrm{~h}$ after oral the same volume corn oil, respectively. All of the cecal samples were collected in sterile environments and containers, snap-frozen in liquid nitrogen, and then stored at $-80^{\circ} \mathrm{C}$.

\subsubsection{DNA Extraction, PCR Amplification and Sequencing}

Microbial DNA was extracted from 24 cecal samples using the E.Z.N.A.®soil DNA Kit (Omega Bio-tek, Norcross, GA, USA) according to manufacturer's protocols. The final DNA concentration and purification were determined by NanoDrop 2000 UV-vis spectrophotometer (Thermo Scientific, 
Wilmington, DE, USA), and DNA quality was checked by $1 \%$ agarose gel electrophoresis. The V3-V4 hypervariable regions of the bacteria $16 \mathrm{~S}$ rRNA gene were amplified with primers $338 \mathrm{~F}\left(5^{\prime}\right.$ ACTCCTACGGGAGGCAGCAG-3') and 806R (5'-GGACTACHVGGGTWTCTAAT-3') by thermocycler PCR system (GeneAmp 9700, ABI, Foster City, CA, USA). The PCR reactions were conducted using the following program: $3 \mathrm{~min}$ of denaturation at $95^{\circ} \mathrm{C} ; 27$ cycles of $30 \mathrm{~s}$ at $95^{\circ} \mathrm{C}, 30 \mathrm{~s}$ for annealing at $55^{\circ} \mathrm{C}$, and $45 \mathrm{~s}$ for elongation at $72^{\circ} \mathrm{C}$; and a final extension at $72{ }^{\circ} \mathrm{C}$ for $10 \mathrm{~min}$. PCR reactions were performed in triplicate $20 \mu \mathrm{L}$ mixture containing $4 \mu \mathrm{L}$ of $5 \times$ FastPfu Buffer, $2 \mu \mathrm{L}$ of $2.5 \mathrm{mM} \cdot \mathrm{L}^{-1} \mathrm{dNTPs}, 0.8 \mu \mathrm{L}$ of each primer $\left(5 \mu \mathrm{M} \cdot \mathrm{L}^{-1}\right), 0.4 \mu \mathrm{L}$ of FastPfu Polymerase, and $10 \mathrm{ng}$ of template DNA. The resulted PCR products were extracted from a 2\% agarose gel and further purified using the AxyPrep DNA Gel Extraction Kit (Axygen Biosciences, Union City, CA, USA) and quantified using QuantiFluor ${ }^{\mathrm{TM}}$-ST (Promega, Madison, WA, USA) according to the manufacturer's protocol.

Purified amplicons were pooled in equimolar and paired-end sequenced $(2 \times 300)$ on an Illumina MiSeq platform (Illumina, San Diego, CA, USA) according to the standard protocols by Majorbio Bio-Pharm Technology Co. Ltd. (Shanghai, China).

\subsubsection{Bioinformatics Analysis}

Raw fastq files were quality-filtered by Trimmomatic and merged by FLASH according to the following criteria: (i) The reads were truncated at any site receiving an average quality score $<20$ over a $50 \mathrm{bp}$ sliding window. (ii) Sequences whose overlap was longer than $10 \mathrm{bp}$ were merged according to their overlap with mismatch no more than $2 \mathrm{bp}$. (iii) Sequences of each sample were separated according to barcodes (exactly matching) and Primers (allowing 2 nucleotide mismatching), and reads containing ambiguous bases were removed. Operational taxonomic units (OTUs) were clustered using UPARSE (version 7.1, http://drive5.com/uparse/) at a 97\% similarity level with a novel "greedy" algorithm that performs chimera filtering and OTU clustering simultaneously. The taxonomy of each 16S rRNA gene sequence was analyzed by RDP Classifier algorithm (http://rdp.cme.msu.edu/) against the Silva (SSU123) 16S rRNA database using confidence threshold of $70 \%$.

\subsection{Statistical Analysis}

Data for each group are presented as mean \pm SD. Statistical significance of different formulations were measured by one-way analysis of variance (ANOVA) followed by the Tukey Kramer multiple comparison test, using SPSS software version 14.0 (SPSS, Chicago, IL, USA), and the statistical significance was expressed by a p-value of less than 0.05 . The main pharmacokinetic parameters of MHO7 was fitted by the average mean of a group in each time point with the Phoenix WinNonLin software version 6.3 (Pharsight, Cary, NC, USA). The gut microbiome analysis was performed using the free online platform of Majorbio Cloud Platform (www.majorbio.com).

\section{Conclusions}

To the best of our knowledge, this is the first report to evaluate the toxicity, pharmacokinetics, and gut microbiome of sesterterpene MHO7. The oil-water distribution coefficients was characterized by $\log \mathrm{P} / \mathrm{D}$ values of MHO7 ranging 0.93-2.48, which is satisfactory for oral preparation [19].

The maximum tolerable dose (MTD) of MHO7 was $2400 \mathrm{mg} \cdot \mathrm{kg}^{-1}$ in mice by oral administration. A rapid, reliable, and sensitive HPLC-MS/MS method was validated for quantitative analysis of MHO7 in mouse biological samples such as plasma and tissues. MHO7 was rapidly distributed in mouse plasma and tissues following a single oral administration. The major target tissue depots of MHO7 in mice was the reproductive organs including uterus, ovary, and oviduct, and the renal excretion might be the main elimination route for MHO7. Additionally, the high concentration of MHO7 in fat is worthy of attention and there was no long-term accumulation in the tissues.

After oral administration of MHO7 for 8-30 h, the diversity and richness of gut community were significantly reduced. Although MHO7 had little influence on the level of dominant microbes at the phylum level, we observed that the relative abundance of 28 genera showed significant change among 
control and treatment groups. Most of the genera influenced belong to Firmicutes (21 of 28), most of these genera (18 of 21) under the order Clostridiales, class Clostridia. The remarkably changed genera classified to clostridia came from family Ruminococcaceae (11 of 18) and Lachnospiraceae (4 of 18). The downregulation of Ruminococcaceae and upregulation of Lachnospiraceae at family level of MHO7 has potential in the treatment of breast cancer [23,24], but the negative effects on the intestine should be noted.

Supplementary Materials: The following are available online at http:/www.mdpi.com/1660-3397/17/12/667/s1, Table S1: Intra-day and inter-day precision and accuracy of HPLC method, Table S2: Log P and Log D values of MHO7 in different time and $\mathrm{pH}$ condition at $37^{\circ} \mathrm{C}$, Table S3: Log P value of MHO7 in different time at $25^{\circ} \mathrm{C}$, Table S4: Method validation of MHO7 for in vitro incubation system, Table S5: Weight of mice organs in acute toxicity test, Table S6: Method validation of MHO7 in plasma, Table S7: Method validation of MHO7 in tissues, Table S8: The concentration of MHO7 in mice tissues, Table S9: The tissue-to-plasma radio of MHO7 in different time, Table S10: Significant different phyla between control and treatment groups, Table S11: Significant different classes between control and treatment groups, Table S12: Significant different orders between control and treatment groups, Table S13: Significant different families between control and treatment groups, Table S14: Significant different genera between control and treatment groups, Figure S1: Specificity of MHO7 in vitro incubation system, Figure S2: Body weight changes of female and male mice within 14 days, Figure S3: Specificity of MHO7 in plasma, Figure S4: Specificity of MHO7 in tissues, Figure S5: Rarefaction and Shannon index curves of OTU level, Figure S6: LDA score by Linear Discriminant Analysis (LDA) Effect Size (LefSe) analysis, Figure S7: MHO7 modulated the composition of gut microbiota at the different taxonomic levels.

Author Contributions: K.H. and W.T. conceived and designed the study; D.W. performed experiments of Log P/D values determination; W.T. and L.Y. isolated and purified MHO7 compound; L.Y. performed the acute toxicity test; W.T. performed the development and verification of HPLC-MS/MS method for the mice biological samples; W.T. and L.Y. performed the pharmacokinetics and tissue distribution experiments; W.T., K.H., and Z.D. wrote and reviewed the manuscript; and K.H. generated research funds and coordinated the project. All authors commented on the manuscript.

Funding: This research was funded by the National Key R\&D Program of China, grant number 2018YFC0311005 and the National Natural Science Foundation of China, grant number 81741153.

Acknowledgments: The authors are grateful to Zhitong Dong, Kang Lu, and Lingjun Sang at Wuhan University for their help on compounds isolation. We also thank Lu Liu, Jielin Hu, Jin Lu, Xin Lei, and Jingjing Guo at Wuhan University for their help on animal sample collection. This research work was financially supported by the National Key R\&D Program of China (No. 2018YFC0311005) and National Natural Science Foundation of China (Grant No. 81741153).

Conflicts of Interest: The authors declare no conflict of interest.

\section{References}

1. Pemberton, T.A.; Chen, M.; Harris, G.G.; Chou, W.K.W.; Duan, L.; Köksal, M.; Genshaft, A.S.; Cane, D.E.; Christianson, D.W. Exploring the influence of domain architecture on the catalytic function of diterpene synthases. Biochemistry 2017, 56, 2010-2023. [CrossRef]

2. Shirley, H.J.; Jamieson, M.L.; Brimble, M.A.; Bray, C.D.C. A new family of sesterterpenoids isolated around the Pacific Rim. Nat. Prod. Rep. 2018, 35, 210-219. [CrossRef] [PubMed]

3. Imhoff, J.F. Natural products from marine fungi-still an underrepresented resource. Mar. Drugs 2016, 14, 19. [CrossRef] [PubMed]

4. Yan, J.; Guo, J.; Yuan, W.; Mai, W.; Hong, K. Identification of Enzymes Involved in Sesterterpene Biosynthesis in Marine Fungi. In Methods in Enzymology; Moore, B.S., Ed.; Marine Enzymes and Specialized Metabolism-Part A; Academic Press: Cambridge, MA, USA, 2018; Volume 604, pp. 441-498.

5. Tian, W.; Deng, Z;; Hong, K. The biological activities of sesterterpenoid-type ophiobolins. Mar. Drugs 2017, 15, 229. [CrossRef] [PubMed]

6. Nicoletti, R.; Vinale, F. Bioactive compounds from marine-derived Aspergillus, Penicillium, Talaromyces and Trichoderma Species. Mar. Drugs 2018, 16, 408. [CrossRef]

7. Choi, B.K.; Trinh, P.T.H.; Lee, H.-S.; Choi, B.-W.; Kang, J.S.; Ngoc, N.T.D.; Van, T.T.T.; Shin, H.J. New Ophiobolin derivatives from the marine fungus Aspergillus Flocculosus and their cytotoxicities against cancer cells. Mar. Drugs 2019, 17, 346. [CrossRef]

8. Zhu, T.; Lu, Z.; Fan, J.; Wang, L.; Zhu, G.; Wang, Y.; Li, X.; Hong, K.; Piyachaturawat, P.; Chairoungdua, A.; et al. Ophiobolins from the mangrove fungus Aspergillus Ustus. J. Nat. Prod. 2018, 81, 2-9. [CrossRef] 
9. Cai, R.; Jiang, H.; Mo, Y.; Guo, H.; Li, C.; Long, Y.; Zang, Z.; She, Z. Ophiobolin-type sesterterpenoids from the mangrove endophytic fungus Aspergillus sp. ZJ-68. J. Nat. Prod. 2019, 82, 2268-2278. [CrossRef]

10. Chai, H.; Yin, R.; Liu, Y.; Meng, H.; Zhou, X.; Zhou, G.; Bi, X.; Yang, X.; Zhu, T.; Zhu, W.; et al. Sesterterpene ophiobolin biosynthesis involving multiple gene clusters in Aspergillus Ustus. Sci. Rep. 2016, 6, 27181. [CrossRef]

11. Zhao, Y.; Zhao, C.; Lu, J.; Wu, J.; Li, C.; Hu, Z.; Tian, W.; Yang, L.; Xiang, J.; Zhou, H.; et al. Sesterterpene MHO7 suppresses breast cancer cells as a novel estrogen receptor degrader. Pharmacol. Res. 2019, 146, 104294. [CrossRef]

12. Lin, L.; Wong, H. Predicting oral drug absorption: Mini review on physiologically-based pharmacokinetic models. Pharmaceutics 2017, 9, 41. [CrossRef] [PubMed]

13. Sugihara, M.; Takeuchi, S.; Sugita, M.; Higaki, K.; Kataoka, M.; Yamashita, S. Analysis of intra-and intersubject variability in oral drug absorption in human bioequivalence studies of 113 generic products. Mol. Pharm. 2015, 12, 4405-4413. [CrossRef] [PubMed]

14. Bergström, C.A.S.; Holm, R.; Jørgensen, S.A.; Andersson, S.B.E.; Artursson, P.; Beato, S.; Borde, A.; Box, K.; Brewster, M.; Dressman, J.; et al. Early pharmaceutical profiling to predict oral drug absorption: Current status and unmet needs. Eur. J. Pharm. Sci. 2014, 57, 173-199. [CrossRef] [PubMed]

15. Fung, T.C.; Olson, C.A.; Hsiao, E.Y. Interactions between the microbiota, immune and nervous systems in health and disease. Nat. Neurosci. 2017, 20, 145-155. [CrossRef] [PubMed]

16. Shreiner, A.B.; Kao, J.Y.; Young, V.B. The gut microbiome in health and in disease. Curr. Opin. Gastroenterol. 2015, 31, 69. [CrossRef] [PubMed]

17. Lynch, S.V.; Pedersen, O. The human intestinal microbiome in health and disease. N. Engl. J. Med. 2016, 375, 2369-2379. [CrossRef]

18. Sommer, F.; Anderson, J.M.; Bharti, R.; Raes, J.; Rosenstiel, P. The resilience of the intestinal microbiota influences health and disease. Nat. Rev. Microbiol. 2017, 15, 630-638. [CrossRef]

19. Proudfoot, J.R. The Evolution of synthetic oral drug properties. Bioorg. Med. Chem. Lett. 2005, 15, 1087-1090. [CrossRef]

20. Rizzatti, G.; Lopetuso, L.R.; Gibiino, G.; Binda, C.; Gasbarrini, A. Proteobacteria: A common factor in human diseases. BioMed Res. Int. 2017, 2017, 9351507. [CrossRef]

21. Shin, N.R.; Whon, T.W.; Bae, J.W. Proteobacteria: Microbial signature of dysbiosis in gut microbiota. Trends Biotechnol. 2015, 33, 496-503. [CrossRef]

22. Lindenberg, F.; Krych, L.; Fielden, J.; Kot, W.; Frøkiær, H.; van Galen, G.; Nielsen, D.S.; Hansen, A.K. Expression of immune regulatory genes correlate with the abundance of specific Clostridiales and Verrucomicrobia species in the equine ileum and cecum. Sci. Rep. 2019, 9, 1-10. [CrossRef] [PubMed]

23. Zhu, J.; Liao, M.; Yao, Z.; Liang, W.; Li, Q.; Liu, J.; Yang, H.; Ji, Y.; Wei, W.; Tan, A.; et al. Breast cancer in postmenopausal women is associated with an altered gut metagenome. Microbiome 2018, 6, 136. [CrossRef] [PubMed]

24. Goedert, J.J.; Jones, G.; Hua, X.; Xu, X.; Yu, G.; Flores, R.; Falk, R.T.; Gail, M.H.; Shi, J.; Ravel, J.; et al. Investigation of the association between the fecal microbiota and breast cancer in postmenopausal women: A population-based case-control pilot study. JNCI J. Natl. Cancer Inst. 2015, 107, 147. [CrossRef] [PubMed]

25. Finnicum, C.T.; Doornweerd, S.; Dolan, C.V.; Luningham, J.M.; Beck, J.J.; Willemsen, G.; Ehli, E.A.; Boomsma, D.I.; Ijzerman, R.G.; Davies, G.E.; et al. Metataxonomic analysis of individuals at bmi extremes and monozygotic twins discordant for BMI. Twin Res. Human Genet. 2018, 21, 203-213. [CrossRef]

26. Beaumont, M.; Goodrich, J.K.; Jackson, M.A.; Yet, I.; Davenport, E.R.; Vieira-Silva, S.; Debelius, J.; Pallister, T.; Mangino, M.; Raes, J.; et al. Heritable components of the human fecal microbiome are associated with visceral fat. Genome Biol. 2016, 17, 189. [CrossRef]

27. Tang, W.W.; Kitai, T.; Hazen, S.L. Gut microbiota in cardiovascular health and disease. Circ. Res. 2017, 120, 1183-1196. [CrossRef]

28. Mokkala, K.; Houttu, N.; Vahlberg, T.; Munukka, E.; Rönnemaa, T.; Laitinen, K. Gut microbiota aberrations precede diagnosis of gestational diabetes mellitus. Acta Diabetol. 2017, 54, 1147-1149. [CrossRef]

29. Xu, W.T.; Nie, Y.Z.; Yang, Z.; Lu, N.H. The Crosstalk between gut microbiota and obesity and related metabolic disorders. Future Microbiol. 2016, 11, 825-836. [CrossRef] 
30. Evans, C.C.; LePard, K.J.; Kwak, J.W.; Stancukas, M.C.; Laskowski, S.; Dougherty, J.; Moulton, L.; Glawe, A.; Wang, Y.; Leone, V.; et al. Exercise prevents weight gain and alters the gut microbiota in a mouse model of high fat diet-induced obesity. PLoS ONE 2014, 9, e92193. [CrossRef]

31. Gui, L.; Chen, S.; Wang, H.; Ruan, M.; Liu, Y.; Li, N.; Zhang, H.; Liu, Z. w-3 PUFAs alleviate high-fat diet-induced circadian intestinal microbes dysbiosis. Mol. Nutr. Food Res. 2019, 1900492. [CrossRef]

32. Wang, R.; Li, S.; Jin, L.; Zhang, W.; Liu, N.; Wang, H.; Wang, Z.; Wei, P.; Li, F.; Yu, J.; et al. Four-week administration of nicotinemoderately impacts blood metabolic profile and gut microbiota in a diet-dependent manner. Biomed. Pharmacother. 2019, 115, 108945. [CrossRef] [PubMed]

33. Zhao, L.; Zhang, Q.; Ma, W.; Tian, F.; Shen, H.; Zhou, M. A combination of quercetin and resveratrol reduces obesity in high-fat diet-fed rats by modulation of gut microbiota. Food Funct. 2017, 8, 4644-4656. [CrossRef] [PubMed]

34. Sun, L.; Jia, H.; Li, J.; Yu, M.; Yang, Y.; Tian, D.; Zhang, H.; Zou, Z. Cecal gut microbiota and metabolites might contribute to the severity of acute myocardial ischemia by impacting the intestinal permeability, oxidative stress, and energy metabolism. Front. Microbiol. 2019, 10, 1745. [CrossRef] [PubMed]

35. Wang, D.; Yan, J.; Teng, M.; Yan, S.; Zhou, Z.; Zhu, W. In utero and lactational exposure to bde-47 promotes obesity development in mouse offspring fed a high-fat diet: Impaired lipid metabolism and intestinal dysbiosis. Arch. Toxicol. 2018, 92, 1847-1860. [CrossRef]

36. Wang, K.; Jin, X.; Li, Q.; Sawaya, A.; Leu, R.; Conlon, M.A.; Wu, L.; Hu, F. Propolis from different geographic origins decreases intestinal inflammation and Bacteroides Spp. populations in a model of dss-induced colitis. Mol. Nutr. Food Res. 2018, 62, 1800080. [CrossRef]

37. Beller, A.; Kruglov, A.; Durek, P.; von Goetze, V.; Hoffmann, U.; Maier, R.; Heiking, K.; Siegmund, B.; Heinz, G.A.; Mashreghi, M.F.; et al. Anaeroplasma, a potential anti-inflammatory probiotic for the treatment of chronic intestinal inflammation. Ann. Rheum. Dis. 2019, 78 (Suppl. 1), A45-A46.

38. Shang, Q.; Shan, X.; Cai, C.; Hao, J.; Li, G.; Yu, G. Dietary fucoidan modulates the gut microbiota in mice by increasing the abundance of Lactobacillus and Ruminococcaceae. Food Funct. 2016, 7, 3224-3232. [CrossRef]

39. van der Beek, C.M.; Dejong, C.H.; Troost, F.J.; Masclee, A.A.; Lenaerts, K. Role of short-chain fatty acids in colonic inflammation, carcinogenesis, and mucosal protection and healing. Nutr. Rev. 2017, 75, $286-305$. [CrossRef]

40. Zhang, D.; Liu, H.; Wang, S.; Zhang, W.; Wang, J.; Tian, H.; Wang, Y.; Ji, H. Fecal microbiota and its correlation with fatty acids and free amino acids metabolism in piglets after a Lactobacillus strain oral administration. Front. Microbiol. 2019, 10, 785. [CrossRef]

41. Huang, C.; Chen, J.; Wang, J.; Zhou, H.; Lu, Y.; Lou, L.; Zheng, J.; Tian, L.; Wang, X.; Cao, Z.; et al. Dysbiosis of intestinal microbiota and decreased antimicrobial peptide level in paneth cells during hypertriglyceridemia-related acute necrotizing pancreatitis in rats. Front. Microbiol. 2017, 8, 776. [CrossRef]

42. Ormerod, K.L.; Wood, D.L.; Lachner, N.; Gellatly, S.L.; Daly, J.N.; Parsons, J.D.; Dal'Molin, C.G.O.; Palfreyman, R.W.; Nielsen, L.K.; Cooper, M.A.; et al. Genomic characterization of the uncultured Bacteroidales family S24-7 inhabiting the guts of homeothermic animals. Microbiome 2016, 4, 36. [CrossRef] [PubMed]

43. Luo, Q.; Cheng, D.; Huang, C.; Li, Y.; Lao, C.; Xia, Y.; Liu, W.; Gong, X.; Hu, D.; Li, B.; et al. Improvement of colonic immune function with soy isoflavones in high-fat diet-induced obese rats. Molecules 2019, $24,1139$. [CrossRef] [PubMed]

44. US FDA. Guidance for Industry: Bioanalytical Method Validation. US FDA: Montgomery County, MD, USA, 2013. Available online: www.fda.gov/downloads/drugs/guidances/ucm368107.pdf (accessed on 15 June 2018).

(C) 2019 by the authors. Licensee MDPI, Basel, Switzerland. This article is an open access article distributed under the terms and conditions of the Creative Commons Attribution (CC BY) license (http://creativecommons.org/licenses/by/4.0/). 